\title{
KINH NGHIỆM ĐIỀU TR! PHẪU THUẬT CHO 9230 BỆNH NHÂN SUY GIÃN TĨNH MẠCH NÔNG CHI DƯỚI TẠI BỆNH VIỆN ĐẠI HỌC Y DƯợC TPHCM
}

\author{
Lê Thị Ngoc Hằng*, Lê Quang Đình*, Trần Minh Bảo Luân*, Lê Thanh Phong*, \\ Lê Thị Thiên Nga*, Đào Duy Phuơng*, Lương Việt Thắng*, Lâm Thảo Cường*, \\ Phan Son An*, Hồ Tất Bằng*, Lê Phi Long*, Nguyễn Hoài Nam*, Trần Thanh V y*
}

\section{TÓMTẮT}

Trong thời gian từ tháng 8 năm 2004 đến tháng 7 năm 2017, có 9230 trường hợp bệnh nhân suy tĩnh mạch chi dưới mạn tính được khám và điều trị phẫu thuật tại Khoa lồng ngực mạch máu bệnh viện Đại học Y dược Tp Hồ Chí Minh. Tỷ lệ nữ trên nam là 2.55 , tuổi trung bình 55 . Phần lớn bệnh nhân phải đứng lâu trên 8 giờ mỗi ngày. Điều trị bằng phương pháp phẫu thuật bao gồm phẫu thuật Stripping và müller bệnh nhân, Müller đơn thuần cho bệnh nhân, can thiệp nội mạch tĩnh mạch (bao gồm RFA tĩnh mạch, Laser tĩnh mạch, Keo sinh học tĩnh mạch, chích xơ tĩnh mạch) bệnh nhân. Kết quả tốt cho $87,8 \%$ các trường hợp. Giãn và suy tĩnh mạch chi dưới mạn tính là một bệnh thường gặp ở phụ nữ. Điều trị bằng phẫu thuật cho kết quả tốt. Tuy nhiên bao giờ cũng phảo bắt đầu và duy trì bằng điều trị nội khoa với thuốc làm tăng tính bền của thành tĩnh mạch và vớ $\mathrm{y}$ khoa. Việc điều trị kết hợp giữa nội khoa - Phẫu thuật và Vớ Y khoa cho kết quả lâu dài

\section{SUMMARY}

\section{TREATMENT OUTCOME OF CHRONIC VENOUS INSUFICIENCY FOR 9230 PATIENTS AT UNIVERSITY MEDICAL CENTER, HO CHI MINH CITY}

From August 2004 to July 2017 there were 9230 patients of CVI (including inpatients and outpatients) at Thoracic and Vascular Surgery Deparment, University Medical Center. The rate of sex (female / male) was 2.55 Average age was 55 . Most of patients had standing time more than 8 hours per day. Medical care was acceptable for all of them. Treament of CVI used in Surgery include phlebectomy by stripping and Müller, only Müller, intravenous intervention(RFA, EVLT, Foamed schlerotherapy). The good outcome was $87.8 \%$. CVI and varicose vein is a common problem, especially in women. Surgical treatment proved to be a good choice when it was combined with phlebologic drugs and pressure stocking.

\section{I. ĐẠT VẤN ĐỀ}

Bệnh lý suy van tĩnh mạch chi dưới có liên quan tới sự trào ngược và suy giảm hồi lưu trong lòng tĩnh mạch. Theo định nghĩa của WHO, suy van tĩnh mạch mạn tính chi dưới là tình trạng tĩnh mạch nông giãn, chậy quanh co và có dòng trào ngược. bệnh lý tiến triển chậm, không rầm rộ, không gây tử vong nhưng theo thời gian sẽ ảnh hưởng đến công việc sinh hoạt và chất lượng cuộc sống của bệnh nhân. Bệnh thường gặp ở các nước phát triển, có liên quan mật thiết tới lối sống, điều trị thường lâu dài và tốn kém, đặc biệt khi có biến chứng. Tần suất mắc bệnh ở người lớn tại Mỹ và các nước Châu Âu chiếm $0.5 \%$ đến $3 \%$ dân số.Tần suất cao của suy giãn tĩnh mạch và loét chi dưới mạn tính gây ảnh hưởng đáng kể lên nguồn lực chăm sóc y tế. Trong một nghiên cứu cộng đồng ở Anh, những vết loét do suy tĩnh mạch gây ra mất khoảng 2 triệu ngày công lao động, và tốn chi phí điều trị khoảng 3 tỷ đôla Mỹ mỗi năm ở Hoa Kỳ.

Ở nước ta, bệnh suy tĩnh mạch mạn tính hai chi dưới là bệnh lý thường gặp nhưng ít được chú ý và nghiên cứu. Bệnh nhân đi khám hoặc được chẩn đoán khi các triệu chứng đã rõ hoặc đã có

\footnotetext{
* khoa Lồng ngực Mạch máu, bệnh viện Đại học Y Dược TP. Hồ Chí Minh

Nguoòi chịu trách nhiệm khoa hoc: PGS. TS. Nguyễn Hoài Nam Ngày nhận bài: 01/05/2018 - Ngày Cho Phép Đăng: 20/05/2018

Phản Biện Khoa học: GS.TS. Bùi Đức Phú PGS.TS. Đặng Ngoc Hùng
} 
biến chứng rối loạn dinh dưỡng về da, viêm tắc tĩnh mạch.

Điều trị ngoại khoa là phương pháp dễ thực hiện, ít tốn kém, không mất nhiều thời gian, cải thiện tình trạng bệnh lý một cách có hiệu quả. Bên cạnh đó, chúng ta không thể bỏ qua vai trò điều trị đa mô thức bao gồm điều trị ngoại khoa (phẫu thuật Stripping+ müller, RFA, Laser, Venaseal), nội khoa, vớ và thay đổi tư thế sinh hoạt. Chúng tôi thực hiện nghiên cứu này nhằm đánh giá kết quả điều trị bệnh suy giãn tĩnh mạch chi dưới mạn tính tại bệnh viện Đai học $\mathrm{Y}$ dược qua đó rút ra một số kinh nghiệm trog việc chỉ định và phối hợp các phương pháp điều trị cho bệnh nhân và tìm hiểu yếu tố nguy cơ nhằm đánh giá tiên lượng bệnh.

\section{II. ĐỐI TƯợNG VÀ PHƯƠNG PHÁP NGHIÊN CÚU}

Tiền cứu, mô tả cắt ngang, đoàn hệ.

Với 9230 trường hợp bệnh nhân suy tĩnh mạch chi dưới mạn tính được khám và điều trị phẫu thuật tại Khoa lồng ngực mạch máu bệnh viện Đại học $\mathrm{Y}$ dược Tp Hồ Chí Minh trong thời gian từ tháng 8 năm 2004 đến tháng 7 năm 2017 .

\section{KẾT QUẢ NGHIÊN CÚU:}

Số lượng bệnh nhân

\begin{tabular}{lc}
\hline Thời gian & Số bệnh nhân \\
\hline Năm 2004-2007 & 976 \\
Năm 2007-2010 & 1274 \\
Năm 2010-2013 & 2736 \\
Năm 2013-2017 & 4244 \\
\hline Tổng số & 9230 \\
\hline
\end{tabular}

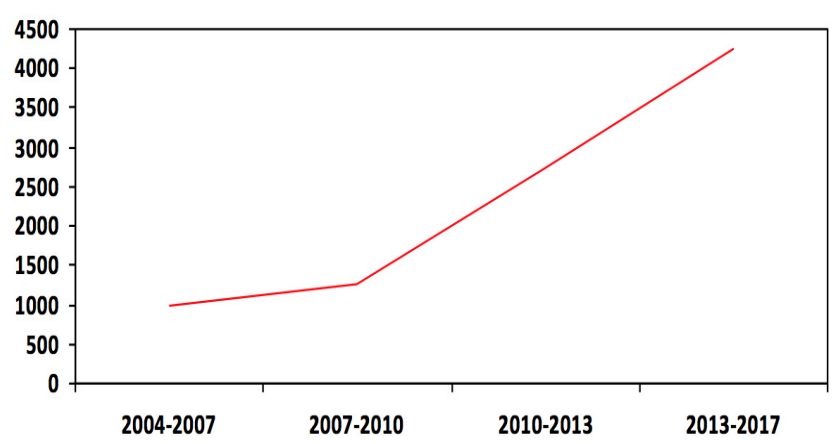

TỶ LẸ: Nữ /Nam : 2.55 (6630/2600)

ĐỘ TUỔI: Trung bình 55 tuổi (già nhất 93 tuổi - nhỏ nhất 21 tuổi). Trong đó $<50$ tuổi chiếm tỷ lệ $47.3 \%$ đây cũng là độ tuổi trong tuổi lao động.

\begin{tabular}{lcc}
\hline \multicolumn{1}{c}{ YẾU TỐ NGUY CO } & $\begin{array}{c}\text { Số bệnh } \\
\text { nhânn }\end{array}$ & $\begin{array}{c}\text { Tỷ lệ } \\
\mathbf{( \% )}\end{array}$ \\
\hline Tuổi >50 & 4864 & 52,7 \\
Béo phì & 3443 & 37.3 \\
Yếu tố gia đình & 2298 & 24.9 \\
Sanh đẻ nhiều (>3 con) & 2889 & 31.3 \\
$\begin{array}{l}\text { Nghề nghiệp và thói quen } \\
\text { đứng lâu (> 8 giờ/ ngày) }\end{array}$ & 7938 & 86 \\
\hline
\end{tabular}

\begin{tabular}{|c|c|c|}
\hline $\begin{array}{c}\text { TRIÊU CHÚN'NG } \\
\text { LẦM SÀNG } \\
\end{array}$ & $\begin{array}{c}\text { Số bệnh } \\
\text { nhânn }\end{array}$ & $\begin{array}{l}\text { Tỉ lệ } \\
\text { (\%) }\end{array}$ \\
\hline Nặng mỏi chân & 8944 & 96.9 \\
\hline Tê, dị cảm & 2104 & 22.8 \\
\hline Đau nhức & 4357 & 47.2 \\
\hline Vọp bẻ về đêm & 3055 & 33.1 \\
\hline Sưng phù chân về chiều & 3009 & 32.6 \\
\hline $\begin{array}{l}\text { Thay đổi tính chất màu } \\
\text { sắc da }\end{array}$ & 1671 & 18.1 \\
\hline Loét chân & 526 & 5.7 \\
\hline
\end{tabular}

\begin{tabular}{cc}
\hline PHÂN ĐỘ THEO CEAP & Tỷ lệ(\%) \\
\hline$C_{2}$ & 43.5 \\
$C_{3}$ & 32.6 \\
$C_{4}$ & 18.1 \\
$C_{5}$ & 3.6 \\
\hline$C_{6}$ & 2.1 \\
\hline
\end{tabular}

\begin{tabular}{ccc}
\hline $\begin{array}{c}\text { PHÂN ĐỘ } \\
\text { VDS }\end{array}$ & Số BN & Tỷ lệ (\%) \\
\hline Độ 1 & 1661 & $18 \%$ \\
Độ 2 & 5907 & $64 \%$ \\
Độ 3 & 1662 & $18 \%$ \\
\hline Tổng số & 9230 & $100 \%$ \\
\hline
\end{tabular}




\section{CÁC PHƯƠNG PHÁP ĐIỀ TRỊ:}

\begin{tabular}{|c|c|c|c|}
\hline \multicolumn{2}{|l|}{ Phương pháp } & Số Bệnh nhân & Tỷ lệ (\%) \\
\hline \multicolumn{2}{|c|}{$\begin{array}{l}\text { Phẫu thuật Stripping+ } \\
\text { Müller }\end{array}$} & 2472 & 26,78 \\
\hline $\begin{array}{l}\text { Phẫu thuật } \\
\text { đơn thuần }\end{array}$ & Müller & 456 & 4,94 \\
\hline $\begin{array}{l}\text { RFA }+ \\
\text { Venaseal }\end{array}$ & Laser+ & 4077 & 44,17 \\
\hline Chích xơ & & 2225 & 24,11 \\
\hline Tổng cộng & & 9230 & 100 \\
\hline
\end{tabular}

MỨC ĐỘ ĐAU SAU PHÃ̃ THUẬT

\begin{tabular}{lcc}
\hline $\begin{array}{l}\text { Mức độ đau } \\
\text { sau thủ thuật }\end{array}$ & $\begin{array}{c}\text { Phẫu thuật } \\
\text { Stripping+ } \\
\text { Müller hoặc } \\
\text { Müller }\end{array}$ & $\begin{array}{c}\text { RFA, Laser, } \\
\text { Keo } \\
\text { Venaseal, } \\
\text { chích xo }\end{array}$ \\
\hline $\begin{array}{l}\text { Không đau hoặc } \\
\text { đau ít không } \\
\text { đáng kể }\end{array}$ & $27 \%$ & $78,6 \%$ \\
$\begin{array}{l}\text { Đau vừa, giới } \\
\text { hạn nhẹ sinh } \\
\text { hoạt và đi lại }\end{array}$ & $63 \%$ & $21,4 \%$ \\
$\begin{array}{l}\text { Đau nhiều, } \\
\text { không thể tự đi } \\
\text { lại và sinh hoạt } \\
\text { được }\end{array}$ & $10 \%$ & $0 \%$ \\
\hline Tổng số & & \\
\hline
\end{tabular}

\section{MỨC ĐỘ CẢI THIỆN LÂM SÀNG THEO} VDS

\begin{tabular}{|c|c|c|}
\hline & Số BN & Tỷ lệ \\
\hline $\begin{array}{l}\text { Có cải thiện rõ rệt, } \\
\text { giảm độ VDS }\end{array}$ & 8103 & $87,8 \%$ \\
\hline $\begin{array}{l}\text { Cải thiện ít, không } \\
\text { cải thiện, hoặc } \\
\text { không rõ rệt }\end{array}$ & 1033 & $11,2 \%$ \\
\hline $\begin{array}{l}\text { Tình trạng nặng } \\
\text { hơn, tăng độ VDS }\end{array}$ & 94 & $1 \%$ \\
\hline Tổng số & 9230 & $100 \%$ \\
\hline
\end{tabular}

\section{TAI BIẾN , BIẾN CHÚ'NG SAU PHẪU THUẬT}

\begin{tabular}{lcc}
\hline & $\begin{array}{c}\text { Phẫu thuật } \\
\text { Stripping+ } \\
\text { Müller hoặc } \\
\text { Müller }\end{array}$ & $\begin{array}{c}\text { RFA, Laser, } \\
\text { Keo } \\
\text { Venaseal, } \\
\text { chích xo }\end{array}$ \\
$\begin{array}{l}\text { Viêm tĩnh } \\
\text { mạch nông } \\
\text { Thương tổn }\end{array}$ & $0 \%$ & $6,6 \%$ \\
$\begin{array}{l}\text { TK lân cận } \\
\text { Huyết khối }\end{array}$ & $28,9 \%$ & $16.9 \%$ \\
$\begin{array}{l}\text { TM sâu } \\
\text { Chảy máu }\end{array}$ & $0 \%$ & $0,9 \%$ \\
$\begin{array}{l}\text { Hoại tử da, } \\
\text { phơng da rộng } \\
\text { Nhiễm trùng }\end{array}$ & $0 \%$ & $0 \%$ \\
$\begin{array}{l}\text { Thuyên } \\
\text { phổi tắc }\end{array}$ & $0 \%$ & $0 \%$ \\
Tử vong & $0 \%$ & $0 \%$ \\
\hline
\end{tabular}

\section{BÀN LUẬN}

Trong khoảng thời gian dài 13 năm 4 tháng, chúng tôi đã khám và điều trị phẫu thuật cho một số lượng lớn bệnh nhân có bệnh lý suy tĩnh mạch mạn tính.

\section{Nguyên nhân và yếu tố thuận lợi}

Tác giả G. Fowkes, Giáo sư chuyên ngành dịch tễ học, Giám đốc của Wolfcon về dự phòng bệnh lý mạch máu ngoại vi Anh quốc, 2001: bệnh lý tĩnh mạch chi dưới là bệnh thường gặp gần khoảng $1 / 3$ dân số phương Tây.Tần suất mắc bệnh gia tăng theo tuổi, có thể có liên quan đến yếu tố cơ địa. Việc đứng lâu là một yếu tố nguy co.

Ngoài ra còn có tình trạng béo phì, những lần có thai trước đây thường kết hợp với sự hiện diện của giãn tĩnh mạch nhưng bằng chứng về mối liên quan này không hằng định.

Jari O Laurikka, Phần Lan, trong một nghiên cứu về dịch tễ cho thấy tỷ lệ nam/ nữ là $1 / 3$, yếu tố thuận lợi để bệnh phát triển là phái nữ, số lần có 
thai, tính di truyền gia đình, tuổi càng lớn càng dễ mắc bệnh, và cuối cùng là hoạt động nghề nghiệp phải đứng lâu. Việc đứng lâu làm bơm cơ kém hoạt độngnên không ép máu tĩnh mạch về đưa đến sự ứ đọng máu tĩnh mạch.

Trong nghiên cứu của chúng tôi, bệnh gặp ở nữ nhiều hơn nam (tỷ lệ nữ/nam là 2.55/1) và hầu hết bệnh nhân có nghề nghiệp đòi hỏi phải đứng lâu (86\%).

\section{Về lâm sàng}

Một nghiên cứu thử nghiệm lâm sàng Edniburgh tại San Diego cho thấy có bảy triệu chứng thường gặp nhất: đau chân, vọp bẻ, mỏi chân, sưng chân, nặng chân, chân không yên, ngứa chân. Trong đó, triệu chứng đau chân là thường gặp nhất chiếm tỷ lệ $17.7 \%$, kế đến là vọp bẻ $14.3 \%$, mỏi chân $12.8 \%$, sưng chân $12.2 \%$. Triệu chứng nặng mỏi chân hầu hết chiếm tỷ lệ giống nhau là $7.5 \%$ và $7.4 \%$. Ngứa chân ít gặp nhất chiếm tỷ lệ $5.4 \%$

Trong lô nghiên cứu của chúng tôi triệu chứng lâm sàng thường gặp nhất là nặng mỏi chân chiếm tỷ lệ $96.9 \%$, kế đến là đau nhức chân $47.2 \%$, vọp bẻ về đêm là $33.1 \%$

\section{Về phân độ lâm sàng CEAP}

Nghiên cứu San Diego thu thập dữ liệu trong cộng đồng trên 2211 trường hợp tuổi từ 40-79, cho thấy tỷ lệ độ $\mathrm{C} 0, \mathrm{C} 1, \mathrm{C} 2, \mathrm{C} 3$ lần lượt là $19 \%$, 51.6\%, 23.3\%, 5.8\%. Suy tĩnh mạch mức độ nặng từ $\mathrm{C} 4$ đến $\mathrm{C} 6$ chiếm tỷ lệ chung là $6.2 \%$.

Ở đây chúng tôi chỉ xếp loại CEAP theo mức độ lâm sàng không tính đến bệnh nguyên và sinh bệnh học. Chúng tôi nhận thấy theo phân loại lâm sàng CEAP độ 2 và 3 chiếm đa số với tỷ lệ $76.2 \%$

Vì thế cho nên việc phân độ CEAP rất cần thiết đề chẩn đoán giai đoạn của bệnh từ đó có thể đưa ra biện pháp điều trị thích hợp cho từng giai đoạn. Ngoài ra việc phân độ lâm sàng còn giúp cho việc điều trị dễ dàng hơn, thống nhất hơn trong cách điều trị của thầy thuốc.

\section{Về kết quả điều trị}

Tác giả Subramonia và cs tại BV King’s Mill, Anh quốc, thực hiện RFA trên 47 trường hợp và so sánh với 41 trường hợp mổ lột $\mathrm{TM}$, khảo sát cảm giác đau sau mổ bằng bảng câu hỏi, cho thấy đau sau RFA ít hơn hẳn so với đau sau khi mổ.

Ở nhóm thực hiện RFA, laser, laser có 78,6\% các trường hợp đều trả lời đau ít, không đáng kể, có thể sinh hoạt và đi lại dễ dàng sau mổ. Còn lại $21,4 \%$ các trường hợp đau vừa, giới hạn và ảnh hưởng nhẹ đến sinh hoạt đi lại. Không có trường hợp nào đau nhiều.

Chúng tôi ghi nhận có $87,8 \%$ có cải thiện rõ rệt các triệu chứng lâm sàng, giảm độ VDS. Các trường hợp cải thiện không nhiều, hoặc không rõ lắm khi được hỏi, chiếm tỷ lệ là 11,2\%.

Hiện nay, vấn đề mối liên quan giữa mức độ nặng của triệu chứng lâm sàng với tình trạng giãn tĩnh mạch, và sự cải thiện lâm sàng sau khi can thiệp phẫu thuật hay các can thiệp nội mạch như RFA hoặc laser, chích xơ... còn có nhiều ý kiến chưa thống nhất

Trong khi đó, nhóm thực hiện mổ lột tĩnh mạch( Stripping + Müller hay Müller đơn thuần), đa số trường hợp (63\%) đều trả lời có đau sau mổ mức độ vừa, giới hạn nhẹ đến sinh hoạt và đi lại. Có $10 \%$ các trường hợp trả lời đau nhiều sau mổ, cần hỗ trợ trong đi lại và sinh hoạt trong những ngày đầu.

Một số nghiên cứu tiền cứu ngẫu nhiên so sánh RFA với mổ lột TM cho thấy RFA có ưu điểm hơn về mặt đau sau mổ, hồi phục sớm hơn, cải thiện chất lượng sống.

Một nghiên cứu thực hiện tại 05 trung tâm ở Mỹ và châu Âu lại ghi nhận rằng các ưu điểm của RFA về tính ít đau, mau hồi phục, thẩm mỹ và cải thiện chất lượng sống chỉ thấy rõ ở trong vòng thời gian đầu trong vòng 04 tháng. Sau 04 tháng, nghiên cứu cho thấy không có sự khác biệt rõ rệt về mức độ cải thiện chất lượng sống. 


\section{Về tai biến và biến chứng}

Chúng tôi ghi nhận : nhóm làm phẫu thuật Stripping và Müller hay Müller đơn thuần tỷ lệ biến chứng DVT 5,4\% cao hơn nhóm can thiệp nội tĩnh mạch là $0,9 \%(\mathrm{p}=0.001)$. Nhìn chung, cả hai phương pháp đều nhẹ nhàng, ít tai biến và biến chứng nguy hiểm như thuyên tắc phổi hay tử vong.

Nghiên cứu của Straub Clinic-Honolulu trên 300 trường hợp thực hiện RFA từ năm 2000, hiệu quả tắc mạch là $97 \%$, biến chứng huyết khối $\mathrm{TM}$ sâu là 2 trường hợp $(0,7 \%)$.

Ở nhóm điều trị bằng RFA, chúng tôi chỉ ghi nhận $6,6 \%$ viêm TM nông, thuyên giảm tốt với điều trị nội khoa. Các trường hợp gặp nhiều $(16,9 \%)$ là BN than phiền tê, hoặc dị cảm, hoặc giảm cảm giác ở vùng đùi, hoặc mặt trong cẳng chân, tương ứng với chi phối cảm giác của các nhánh bì đùi trước và thần kinh hiển. Hiện tượng này là do tác động nhiệt làm bỏng các nhánh thần kinh nói trên, do việc chích dung dich làm mát xung quanh TM hiển để cách nhiệt khi phát xung chưa tốt.

Ở nhóm điều trị bằng mổ lột $\mathrm{TM}$, tỷ lệ tổn thương thần kinh hiển khá cao $(28,9 \%)$. BN thường than phiền tê và mất cảm giác vùng mặt trong cẳng chân và mắt cá trong. Tuy nhiên không có trường hợp nào gây ra ảnh hưởng lớn đến sinh hoạt và công việc của người bệnh sau mổ. Ở nhóm này chúng tôi cũng gặp $2 \%$ nhiễm trùng vết mổ nhưng cũng đáp ứng tốt với điều trị bảo tồn và săn sóc tại chỗ.

Tương tự, tác giả Helmy Elkaffas tại ĐH Cairo-Ai Cập thực hiện so sánh ngẫu nhiên 90 trường hợp RFA với 90 trường hợp mổ lột $\mathrm{TM}$, theo dõi 24 tháng, ghi nhận nhóm RFA có tỷ lệ biến chứng thấp hơn $(\mathrm{P}=0,02)$, ngày nằm viện ít hơn $(\mathrm{P}=0,001)$, tuy nhiên chi phí điều trị cao hơn nhiều $(\mathrm{P}=0,003)$.

\section{KẾT LUẬN}

Giãn và suy tĩnh mạch chi dưới mạn tính là một bệnh thường gặp ở phụ nữ rất phổ biến trong dân số. Tuy nhiên từ nhiều năm nay, bệnh chưa được chú ý trong chẩn đoán và điều trị.

Điều trị bằng phẫu thuật cho kết quả tốt, cải thiện triệu chứng lâm sàng cũng như nâng cao chất lượng cuộc sống cho người bệnh. Tuy nhiên việc lựa chọn phương pháp phẫu thuật hiện vẫn còn bàn cãi, nhưng không thể phủ nhận ưu điểm của phương pháp can thiệp nội tĩnh mạch giúp cho người bệnh hồi phục nhanh hơn, ít đau hơn cũng như mang tính thẩm mỹ hơn.

\section{TÀI LIỆU THAM KHẢO}

1. Lê Phi Long, Văn Minh Trí, Nguyễn Hoài Nam (2008), "Kết quả điều trị suy tĩnh mạch mạn tính chi dưới”, Y học TP.HCM, Tập 12, Phụ bản số 4, Tr 312-316

2. Ciucci J. (1999). Quality control in varicose vein surgery: significance and feasibility.

3. Jari. O. Laurikka. Risk indications for varicose veins in forty to sixty Y.O in the tempere varicose vein study. World Journal of Surgery. June 2002, V. 26, N. 6. p 648.

4. John j. Bergan. Varicose veins: treatment by surgery and sclerotherapy. Vascular Surgery, vol. 2, 2000, p. 2007-2021.

5. Khirurgiia (Mosk). Surgical Technologies in the treatment of lower extremity varicose disease. (1): 10-5 Related Articles, Book, 2002.

6. Robert L. Kistner, Elna M. Masuda. A practical approach to the diagnosis and classification of chronic venous disease. Vascular Surgery, vol. 2, 2000, p. 19901999. 